\title{
Role of hydromechanical properties of plant roots in unsaturated soil shear strength
}

\author{
Anthony K. Leung ${ }^{\text {i) }}$, David Boldrin ${ }^{\text {ii) }}$, Ali A. Karimzadeh ${ }^{\text {iii) }}$ and Anthony G. Bengough ${ }^{\text {iv) }}$ \\ i) Assistant Professor, Department of Civil and Environmental Engineering, The Hong Kong University of Science and Technology, \\ Hong Kong SAR \\ ii) Post-doctoral research associate, Division of Civil Engineering, University of Dundee, Dundee, UK \\ iii) Research student, Department of Civil and Environmental Engineering, The Hong Kong University of Science and Technology, \\ Hong Kong SAR \\ iv) Professor, Division of Civil Engineering, University of Dundee, Dundee, UK; The James Hutton Institute, Dundee, UK
}

\begin{abstract}
Plants increase slope stability through mechanical reinforcement by roots and transpiration-induced matric suction (hence increase in soil shear strength; known as hydrological reinforcement). The effects of root water status on root biomechanical properties (e.g. volume change and tensile properties), and eventually the shear strength of rooted soil, have not yet been fully investigated. This paper studies the hydromechanical properties of plant roots and estimates how these properties may affect unsaturated soil strength. The root water retention curve (RWRC), is introduced as a new concept to relate root water content and root suction. Unsaturated shear strength equations are hypothesised to utilise RWRC to couple the mechanical and hydrological reinforcement by plant roots. The potential importance of considering the effects of root hydromechanical properties on soil shear strength is highlighted, together with the need to fully test and develop the underlying models.
\end{abstract}

Keywords: vegetation, shear strength, hydromechanical properties, soil water retention, root water retention

\section{INTRODUCTION}

Soil bioengineering using plants has been considered to be an environmentally-friendly technique for shallow slope stabilisation ( $\mathrm{Ng}$ et al. 2019). Plants have previously been thought to affect the soil shear strength via mechanical root reinforcement (e.g., Stokes et al. 2009; Liang et al. 2017), rainfall interception by canopy (e.g., Barbier et al. 2009) and transpiration-induced soil matric suction (e.g., Rahardjo et al. 2014). Scanlan and Chinz (2009) propose that plant roots occupy soil pore space and alter the soil water retention curve (SWRC) and hydraulic conductivity function (SHCF). $\mathrm{Ng}$ et al. (2016) and Ni et al. (2019) derived formulae to quantify the root-induced changes of these hydraulic properties.

A major assumption that has been implicitly made in the existing literature is that roots subjected to testing were fully hydrated with root water content remaining unchanged. Indeed, Yang et al. (2016) show that root water content can affects the tensile properties of roots significantly. The impact of this phenomenon on the shear strength of unsaturated rooted soil is not clear.

This study aims (i) to study the responses of root volume and root tensile properties under changing root water content conditions; and (ii) to attempt to formulate new shear strength equations to account for the effects of the hydromechanical behaviour of roots.

\section{HYDROMECHANICAL PROPERTIES OF PLANT ROOTS}

\subsection{Root water retention curve}

A root water retention curve (RWRC; analogous to a SWRC) may be constructed by relating independently measured root water content and root water potential (or root suction).

Ulex europaecus L. (common name: Gorse), which is a woody perennial shrub species native to Europe, was used for testing (Boldrin et al., 2018). After sampling and washing the roots free from soil, the roots with a diameter range of $2.8-4.1 \mathrm{~mm}$ were cut into 20-30 mm segments. These segments were hydrated in distilled water for $24 \mathrm{~h}$ and, subsequently the weight was measured by an electronic 4-decimal-place balance. Each root sample was left on a bench for natural drying. At regular time intervals of dehydration, root suction was measured by a dew-point hygrometer (WP4-T; Decagon Devices), while the mass of each root was determined by weighing. The test was stopped when root suction reached $7 \mathrm{MPa}$. Finally, all root samples were oven-dried at $70{ }^{\circ} \mathrm{C}$ until a constant weight was recorded. Root water content is defined as the ratio of the mass of water to root dry biomass, like the definition of gravimetric water content in soil. 
Fig. 1 relates the measured root water content to root suction - RWRC. The initial root diameter (i.e., the value at fully hydrated condition) appears not to affect the RWRC substantially. The RWRCs can be fitted by the van Genuchten (1980)'s equation reasonably well, though the equation is typically used for fitting SWRC. Compared to mineral soil, the plant roots have larger capacity to hold water $\left(>2.0 \mathrm{~g} \mathrm{~g}^{-1}\right)$. The roots also need a much higher suction $(\sim 0.5-1 \mathrm{MPa})$ to start dehydrate. It is worth-noting that at 7 to $8 \mathrm{MPa}$ of root suction, the roots still retained $20 \%$ of their initial water content $\left(0.5 \mathrm{~g} \mathrm{~g}^{-1}\right)$.

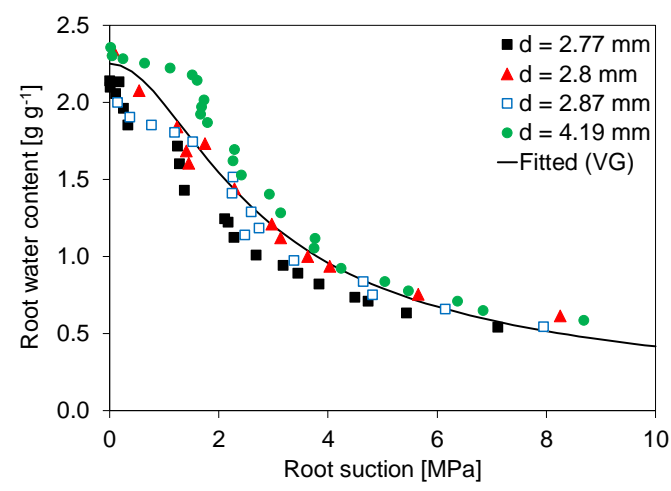

Fig. 1. Root water retention curve of Ulex europaecus L. (Boldrin et al. 2018). The fitting parameters of van Genuchten (1980)'s equation are $a=0.56 \mathrm{MPa}^{-1} ; n=2 ; m=1-1 / n=0.5$.

\subsection{Root volume change}

Another set of roots of $U$. europaecus $(\mathrm{n}=158)$ with a segment length of $150 \mathrm{~mm}$ were subjected to dehydration. Root diameter changes were recorded. Fig. 2 relates the relative root diameter (final diameter over the initial value right after root hydration) with root water loss. Roots subjected to progressive dehydration showed significant root shrinkage and thus a decrease in root diameter. When water loss increased to $0.7 \mathrm{~g} \mathrm{~g}^{-1}$, the shrinkage of root diameter was up to $30 \%$.

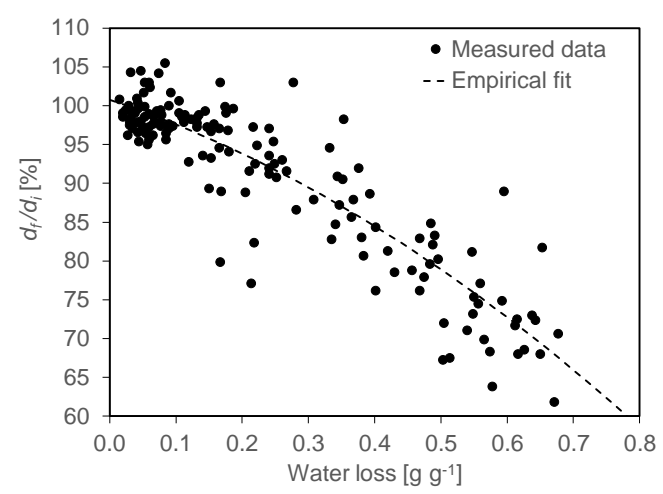

Fig. 2. Relation between root water loss $\left(w_{L}\right)$ and relative diameter (in percentage; Boldrin et al. 2018). [\% $d_{f} / d_{i}=100.78-$ $\left.28.74 w_{L}-30.00 w_{L}^{2}, \mathrm{R}^{2}=0.83, n=158\right]$

\subsection{Root tensile properties}

Effects of root water content (or root suction) on the root tensile properties (i.e., hydromechanical properties of plant roots) were determined. After each step of root dehydration, displacement-controlled $\left(2 \mathrm{~mm} \mathrm{~min}^{-1}\right)$ root tensile tests were conducted by using a universal testing frame (Instron 5966; Norwood, MA, USA). The root breakage force was recorded. The root segment length was $150 \mathrm{~mm}$ and the length between the pair of clamps (which held the root sample in place) was $60 \mathrm{~mm}$.

Fig. 3 compares the tensile stress-strain relations of a fully hydrated root and a $24 \mathrm{~h}$-dried root. Root tensile stress was calculated by diving the mobilised root force by the root cross-section area before testing, while root tensile strain was obtained by normalising the extension by the initial root length of $60 \mathrm{~mm}$. The response of the hydrated root is elasto-plastic. Strain-hardening, ductile response is observed until the root broke at a strain of $13.8 \%$. On the contrary, the response of drier root is elastic and brittle, characterised with a much higher stiffness and higher breakage stress at a much lower strain than the hydrated root. Root water status thus plays a crucial role in the root mechanical behaviour.

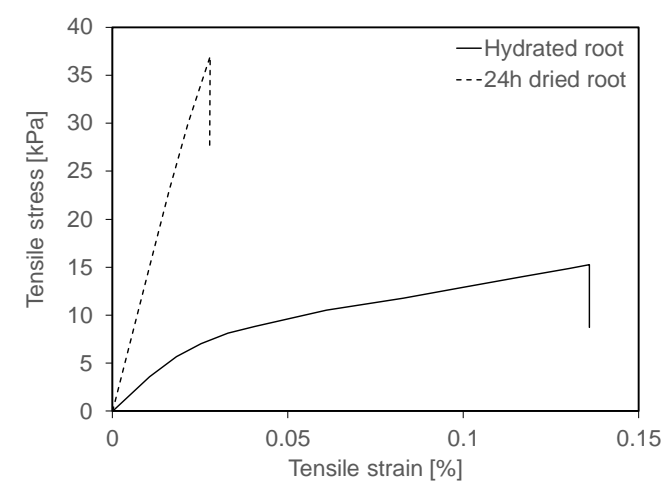

Fig. 3. Stress-strain curves for a hydrated root sample $(d=1.48$ $\mathrm{mm}$; water content, $\left.w_{c}=1.89 \mathrm{~g} \mathrm{~g}^{-1}\right)$ and a root sample air-dried for $24 \mathrm{~h}\left(d=1 \mathrm{~mm} ; w_{c}=0.11 \mathrm{~g} \mathrm{~g}^{-1}\right)$ (Boldrin et al. 2018)

Fig. 4 relates the root tensile strength $\left(T_{r}\right.$; obtained by using the final root diameter after dehydration) to root water content $\left(w_{c}\right)$, for root diameters less than $7 \mathrm{~mm}$. The root tensile strength was significantly affected by water content ( $p$-value $<0.001$, by one-way analysis of variance). A power law relation is found. When the root water content dropped below $0.5 \mathrm{~g} \mathrm{~g}^{-1}$, the root tensile strength appears to increase exponentially.

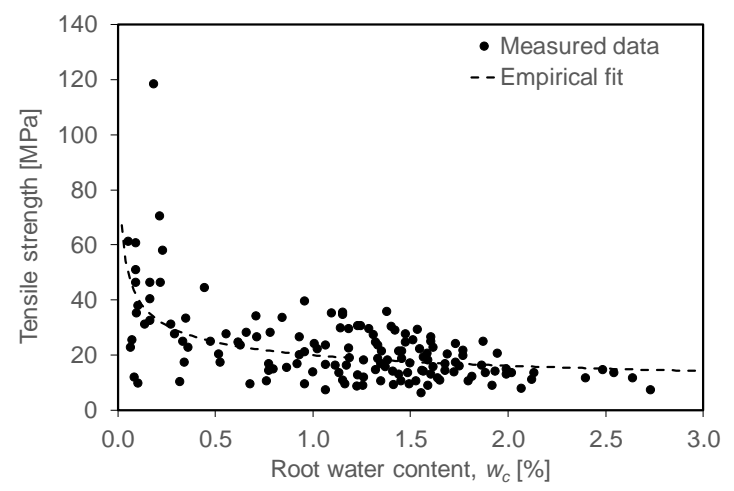

Fig. 4. Relation between root water content and tensile strength $(\mathrm{n}=188)$. [ $\left.T_{r}=19.95 w_{c}{ }^{-0.31}, \mathrm{R}^{2}=0.30\right]$ (Boldrin et al. 2018). 


\section{THEORETICAL CONSIDERATION}

Based on the experimental evidence shown in Figs 1 -4 , plant roots should not be exclusively considered to affect the strength of unsaturated rooted soil through only mechanical reinforcement and plant transpiration. Change in root tensile properties due to the dehydration of roots, say during plant transpiration, may affect the amount of tensile stress transferred to soil. In other words, the hydrological effects of plant transpiration affect the soil strength not only via an increase in soil matric suction, but also root suction (via RWRC) and hence the change in root mechanical properties.

This section aims to utilise existing knowledge of unsaturated soil mechanics and makes the first attempt to model the coupling of the mechanical and hydrological effects of plant roots on soil strength.

\subsection{Hydraulic properties of rooted soil}

The hydraulic properties of unsaturated rooted soils considered are SWRC and SHCF. Ni et al. (2019) considered that plant roots would occupy soil pore size and cause a change in soil void ratio. Accordingly, the following void-ratio function was proposed:

$$
e=\frac{e_{0}-(1-\eta) R_{v}\left(1+e_{0}\right)}{1+(1-\eta) R_{v}\left(1+e_{0}\right)}
$$

where $e$ is the void ratio of rooted soil; $e_{0}$ is the void ratio of the bare soil; $R_{v}$ is the root volume ratio, which is defined as the total volume of roots per unit volume of soil; and $\eta$ is the fraction of the "return" of the soil pore space (in volume) due to root shrinkage by, for example, decay or water loss (Fig. 2). Hence, based on the void-ratio dependent SWRC proposed by Gallipoli et al. (2003), the SWRC of rooted soil can be derived:

$$
S_{e}=\frac{S-S_{r}}{1-S_{r}}=\left[1+\left(\frac{s e^{m_{4}}}{m_{3} \exp \left(k \frac{e_{r}}{e_{r 0}}\right)}\right)^{m_{2}}\right]^{-m_{1}}
$$

where $S$ is the current soil degree of saturation; $S_{e}$ and $S_{r}$ is the effective and residual degree of saturation; $s$ is the matric suction of soil; and $m_{1}, m_{2}, m_{3}, m_{4}$ are the model parameters. Assuming that the void ratio of soil has negligible effects on SWRC at high suction range, the product, $m_{1} m_{2} m_{4}$, is fixed to be 1 (Gallipoli et al. 2003). On the other hand, the parameter $k$ is introduced to control the rate of change of air-entry value due to the formation of soil macro-pores upon root shrinkage (Vergani and Graf 2015). Ni et al. (2019) suggested $k$ to be a constant of 10 for coarse-grained material. $e_{r}$ in Eq. (2) is the void ratio "returned" from root shrinkage:

$$
e_{r}=\frac{\eta R_{v}\left(1+e_{0}\right)}{1+(1-\eta) R_{v}\left(1+e_{0}\right)}
$$

while $e_{r 0}$ is the void ratio occupied by roots when $\eta=0$.

The void-ratio equation derived in Eq. (1) was used to also modify the Kozeny-Carman (KC) equation for considering the plant root effects on saturated hydraulic conductivity $\left(k_{s}\right)$ of coarse-grained soil ( $\mathrm{Ni}$ et al. 2019):

$$
k_{s}=\frac{A}{\exp \left(+k \frac{e_{r}}{e_{r 0}}\right)} \frac{e^{3}}{(1+e)}
$$

where $A$ is an empirical factor that depends on the pore shape and tortuosity of water flow channels, wetted surface per unit volume of soil particles, the unit weight of water and the viscosity (Carrier 2003). A value of 3 $\mathrm{x} 10^{-5} \mathrm{~s} / \mathrm{m}$ was adopted in this study to approximate the saturated permeability of the slightly clayey sand (see later), as estimated by Leung et al. (2018). Hence, the unsaturated hydraulic conductivity, $k_{\text {unsat }}$, can be derived by van Genuchten (1980)'s equation:

$$
k_{\text {unsat }}=k_{S} \cdot S_{e}{ }^{0.5}\left[1-\left(1-S_{e}^{1 / m_{1}}\right)^{m_{1}}\right]^{2}
$$

\subsection{Shear strength equations}

Consider an unsaturated soil that obeys the shear strength equation proposed by Vanapalli et al. (1996), which takes into account the effects of SWRC:

$$
\tau=c^{\prime}+\left(\sigma_{n}-u_{a}\right) \tan \phi^{\prime}+\left(u_{a}-u_{w}\right)\left[\left(\tan \phi^{\prime}\right)\left(\frac{S-S_{r}}{1-S_{r}}\right)\right]_{(6)}
$$

where $\tau$ is shear strength; $c^{\prime}$ is effective cohesion; $\sigma_{n}$ is normal stress; $u_{a}$ is pore-air pressure; $u_{w}$ is pore-water pressure; and $\phi^{\prime}$ is effective friction angle. Note that $\left(\sigma_{n}\right.$ $\left.-u_{a}\right)$ and $\left(u_{a}-u_{w}\right)$ is referred to as net normal stress and matric suction $(s)$, respectively. When plant roots exist, the shear strength equation may be modified by adding a term so-called "root cohesion" $\left(c_{r}\right)$ in Eq (6), to account for the effect of mechanical root reinforcement:

$$
c_{r}=k_{r} \cdot A_{r} \cdot T_{r}
$$

where $k_{r}$ is an empirical root-soil interaction factor that depends on root orientation and root breakage process, taken to be 0.318 for $U$. europaeus (Liang et al. 2017); $A_{r}$ is root-area ratio (RAR; ratio between cross-section area of roots crossing a shear plane and total area of the shear plane). Since the root tensile strength (defined by the final root diameter after dehydration) is a function of root water content (Fig. 4), the following empirical equation may be used.

$$
T_{r}=\alpha w_{c}^{\beta}
$$

where $\alpha$ and $\beta$ are empirical constants and specific to species. To account for the dependency of root water content on root diameter (Fig. 2), the empirical equation shown in the figure caption can be used.

\subsection{Soil-root moisture exchange}

To determine root water content, root suction must be known, through the RWRC (e.g., Fig. 1). As a first approximation, Gardner (1960)'s theory of water flow to plant roots may be considered and adopted in this study. Gardner (1960) considers radial water flow to an infinitely-long cylindrical root (with a diameter $d_{r}$ ) in 
an infinite, two-dimensional sol medium:

$$
s_{r}-s=\frac{q}{4 \pi k_{\text {unsat }}} \ln \left[\left(\frac{r}{d_{r}}\right)\right]
$$

where $s_{r}$ is root suction; $q$ is rate of root-water uptake; $k_{\text {unsat }}$ is soil hydraulic conductivity function varying with soil matric suction $s$ (through Eq. (5)); $r$ is the distance where $s$ is known/measured.

Hence, by knowing the root traits (diameter, RAR, $R_{v}$ ), hydromechanical properties of root (RWRC), soil hydraulic properties (SWRC and SHCF) and root-water uptake rate, the shear strength of unsaturated rooted soil that takes into account the coupled mechanical and hydrological effects of plant roots can be estimated.

The calculation steps are: for a root-water uptake rate $(q)$, root diameter $\left(d_{r}\right)$ and matric suction $(s)$, root suction $\left(s_{r}\right)$ can be determined by Eq. (9). Via RWRC, the root suction can be mapped to a root water content $\left(w_{c}\right)$, assuming the root is non-hysteretic. On one hand, $w_{c}$ can be used to determine the root tensile strength $\left(T_{r}\right)$ via Eq. (8), hence root cohesion $\left(c_{r} ;\right.$ Eq. (7)). $w_{c}$ can also be used to determine the diameter after dehydration (Fig. 2). This new diameter is then used to inform $\eta$ in the void-ratio equation (1) and hence the determination of the SWRC and SHCF of the rooted soil (Eqs (2), (4) and (5)). The new diameter is also used to update the $A_{r}$ in Eq. (7). Eventually, the shear strength of unsaturated soil due to the simultaneous changes of $c_{r}$ and $S_{e}$ can be estimated, via Eq. (6).

\section{HYDROMECHANICAL REINFORCEMENT}

This section utilises Eqs (1) - (9) to investigate the relative contributions of the different factors of soil and roots to soil shear strength. The soil considered in this analysis is slightly clayey sand $\left(e_{0}=0.733\right)$ studied by Boldrin et al. (2017). The SWRC, measured and fitted, is shown in Fig. 5(a). The shear strength parameters, $c$ ' and $\phi^{\prime}$, are set to be 0 and $40^{\circ}$, respectively.

Regarding plant, Ulex europaeus L. is considered so the observed hydromechanical behaviour of the roots and the empirical relations in Section 2 can be utilised in the analysis. Ranges of typical root geometry and morphology in terms of $R_{v}\left(0-0.05 \mathrm{~mm}^{3} / \mathrm{mm}^{3}\right)$, RAR $\left(0-0.05 \mathrm{~m}^{2} / \mathrm{m}^{2}\right)$ and diameter $(0-5 \mathrm{~mm})$ are covered to investigate their sensitivity to the hydromechanical reinforcement. A potential range of the rate of root-water uptake $(q)$ between $1 \times 10^{-6}$ and $1 \times 10^{-4}$ $\mathrm{mL} / \mathrm{s} / \mathrm{m}$ is also considered in the analysis.

The drying SWRCs of rooted soil predicted by Eq. (2) at $R_{v}$ of 0.05 and $0.15 \mathrm{~mm} / \mathrm{mm}^{3}$ are given in Fig. 5(a). As $R_{v}$ increases, the air-entry value (AEV) increases due to the increased occupancy of soil pore space by (hydrated) roots and hence the reduction of soil void ratio. Root occupancy also affects the SHCF (Fig. 5(b)). While $k_{s}$ reduces (Eq. 4), a rightward shift of the curve is found due to the increase of AEV.

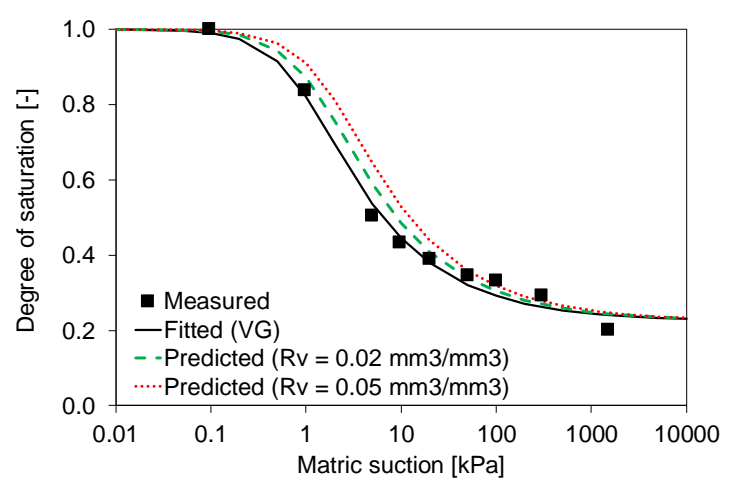

(a)

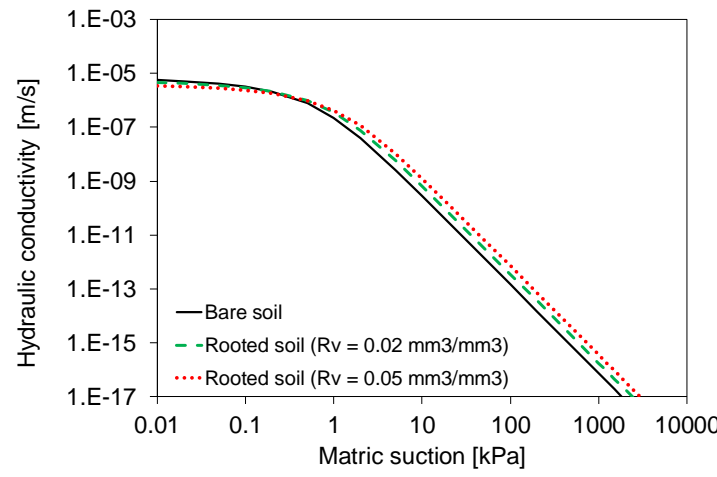

(b)

Fig. 5. (a) SWRC and (b) SHCF of the slightly clayey sand, with and without reinforced by hydrated roots. Measured data in (a) is from Boldrin et al. (2017) and they are best-fitted by Eq. (2) with $m_{1}=0.342, m_{2}=1.52, m_{3}=0.263$ and $m_{4}=4.021$.

Fig. 6 depicts the predicted relations between soil matric suction and shear strength of unsaturated soil, with and without reinforcing by hydrated or dehydrated roots. For bare soil, as expected, the increase in matric suction increases soil shear strength nonlinearly, due to the nonlinearity of the SWRC (Vanapalli et al. 1996). When reinforcing by hydrated roots, the addition of the constant root cohesion to the shear strength equation (6) causes an upward shift of the strength-suction curve. The root cohesion is constant in this case because for a given RAR, the roots were considered not losing their moisture for the entire range of soil matric suction.

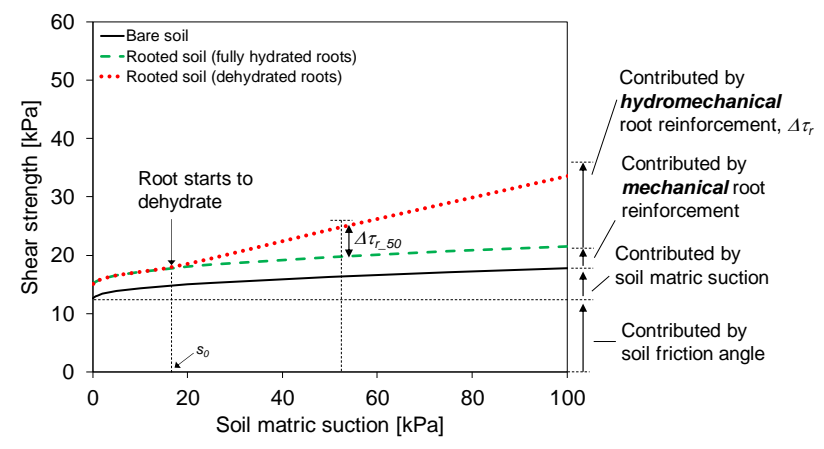

Fig. 6. Relative contributions of different factors of soil and plant roots to the shear strength of unsaturated rooted soil. $q=1 \times 10^{-4}$ $\mathrm{ml} / \mathrm{m} / \mathrm{s} ; d_{r}=2 \mathrm{~mm} ; R_{v}=0.05 \mathrm{~mm} / \mathrm{mm}^{3}$ 
When the effect of root dehydration was considered, additional shear strength is provided when exceeding a matric suction. This threshold value $\left(s_{0}\right)$ is related to the root suction where roots start to dehydrate according to their RWRC (Fig. 1). It is important to note that the root suction where root starts to dehydrate $(\sim 0.2 \mathrm{MPa}$; see Fig. 1) and the matric suction where soil starts to desaturate $(0.2-2 \mathrm{kPa}$; see Fig. 5(a)) are not the same due to the hydraulic resistance of moisture exchange between soil and root, as expressed in Eq. (9). As root dehydrates further and losses its water content, the root tensile strength, and hence root cohesion and soil shear strength, increase- this additional increase in strength is associated with transpiration-induced changes in root hydromechanical properties. Interestingly, although the decrease in root diameter due to dehydration causes a decrease in RAR (i.e., $A_{r}$ in Eq. (7)), there was still an overall increase in soil shear strength. This suggests that upon root dehydration, the effect of the increase in root tensile strength dominates that of the decrease in RAR, hence resulting in a net increase in $c_{r}$.

\section{SENSITIVTIVITY ANALYSIS}

The importance of root shrinkage (i.e., root diameter reduction due to dehydration) on shear strength is studied. Fig. 7 compares the strength-suction relations at different values of $q$, with and without considering the effect of root shrinkage. For "non-shrinkable" case, the parameter $\eta$ is set to be 0 in Eq. (1). This means that the soil pore space being occupied by the roots would not be "returned" due to root shrinkage - both the SWRC and SHCF of rooted soil remained unchanged. The difference of soil shear strength provided by "shrinkable" and "non-shrinkable" roots grows with an increase in $q$. At a given $q$, root shrinkage increases soil void ratio (Eq. (1)), reduces $k_{\text {unsat }}$ (Eq. (5)), increases hydraulic resistance of soil-root moisture exchange (Eq. (9)) and eventually leads to a higher root suction and root cohesion. When $q$ is lower than $1 \times 10^{-6} \mathrm{ml} / \mathrm{m} / \mathrm{s}$, the effects of root shrinkage on hydromechanical root reinforcement is almost negligible.

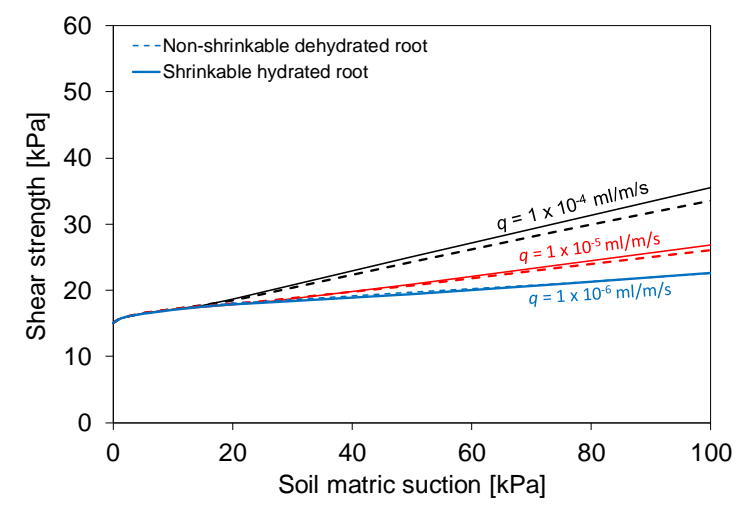

Fig. 7. Effects of root shrinkage on shear strength at $q$ of $1 \times 10^{-4}$, $1 \times 10^{-5}$ and $1 \times 10^{-6} \mathrm{ml} / \mathrm{m} / \mathrm{s} . d_{r}=2 \mathrm{~mm}$ and $R_{v}=0.05 \mathrm{~mm} / \mathrm{mm}^{3}$.
Among the root traits required in the formulation, $R_{v}$ is not always readily available nor easy to determine without washing out the root system or performing three-dimensional root imaging ( $\mathrm{Ng}$ et al. 2016). Hence, any root-induced changes in both SWRC and SHCF cannot be straightforwardly deduced by Eqs (1), (2) and (5). Fig. 8 shows how the soil shear strength changes when the effects of the root-induced changes in SWRC and SHCF are ignored. Note that the y-axis in the figure is expressed as the difference of shear strength at a matric suction of $50 \mathrm{kPa}$ with and without considering the effects of root-induced changes in the two hydraulic properties. For the given ranges of $R_{v}$ and $q$, positive value is always found, meaning that the shear strength is overestimated when the effects are ignored. The overestimation is more significant when $R_{v}$ or/and $q$ is/are higher. Indeed, increasing $R_{v}$ means a decrease in void ratio (Eq. (1)), an increase in $k_{\text {unsat }}$ at $50 \mathrm{kPa}$ matric suction (Fig. 5(b)), a decrease in root suction (Eq. (9)) and hence the root cohesion.

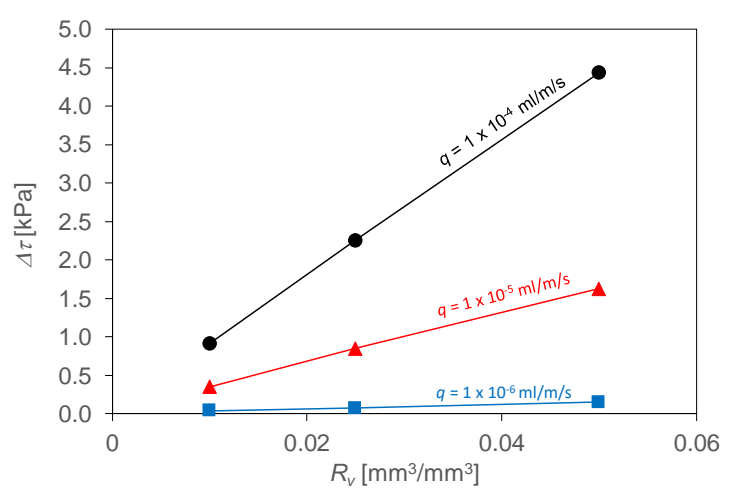

Fig. 8. Effects of root-induced change in soil hydraulic properties on shear strength at soil matric suction of $50 \mathrm{kPa}$ at different values of $R_{v}$ and $q . d_{r}=2 \mathrm{~mm}$.

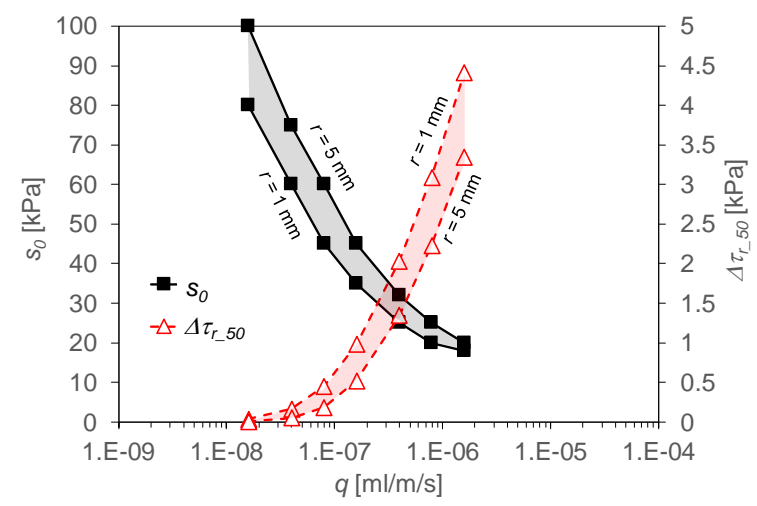

Fig. 9. Effects of $q$ on $s_{0}$ (left axis) and $\Delta \tau_{r_{-} 50}$ (right axis) for a range of average root diameter between 1 and $5 \mathrm{~mm}$.

Fig. 9 depicts the influences of $q$ on the threshold matric suction $\left(s_{0}\right)$ and $\Delta \tau_{r_{-} 50}$ (i.e., the difference of soil shear strength reinforced by dehydrated and hydrated roots at a matric suction of $50 \mathrm{kPa}$; refer to Fig. 6). The analysis shows that with a logarithm increase in $q, s_{0}$ reduces whereas $\Delta \tau_{r-50}$ increases, almost exponentially. The analysis results imply that under higher root-water 
uptake rate (or high transpiration rate), root dehydration takes place and starts contributing to the soil strength at lower threshold suction. When $q$ exceeds $1 \times 10^{-7}$ $\mathrm{ml} / \mathrm{m} / \mathrm{s}$, the strength provided by the hydromechanical properties of plant root becomes not negligible. Clearly, both $s_{0}$ and $\Delta \tau_{r_{-} 50}$ depend not only on $q$ but also the average root diameter. Roots with larger diameter dehydrate at higher $s_{0}$. Thus, the dehydration effects contribute less to the increase in soil shear strength.

\section{REMARKS AND FUTURE WORK}

Decrease in root water content due to root suction during uptake shrinks root volume and increases tensile strength. This paper introduces a new property, root water retention curve (RWRC), to define the relation between root water content and root suction. It is a key property to characterise the hydromechanical properties of plant roots. Preliminary analysis show that, in addition to the mechanical reinforcement by hydrated root and plant transpiration-induced soil matric suction, the amount of root suction induced by water uptake may contribute to further increase in shear strength.

The analysis presented in this study, however, has made important assumptions that need to be properly tested. For example, the formulation considers only the physical root occupancy in soil pore space; biochemical effects (e.g., release of hydrophobic organic matter) on SWRC and SHCF are ignored. Also, the equation used to describe the soil-root moisture exchange is simplified - effects of rhizosphere on soil-root hydraulic resistance is not included, if known. Nonetheless, data about shear strength of unsaturated rooted soil, alongside with the information of root traits, especially RWRC, is lacking. More research to quantify the coupled hydromechanical reinforcement of roots to soil shear strength is clearly needed to better understand root reinforcement mechanisms.

\section{ACKNOWLEDGEMENTS}

The research grant, no. GRF16212818, provided by the Research Grant Council (RGC) of the Hong Kong Special Administrative Region is acknowledged. Giles Laverack (Scotia Seeds) provided the root material for this study. The James Hutton Institute receives funding from the Scottish Government.

\section{REFERENCES}

1) Barbier, S., Balandier, P. and Gosselin, F. (2009) Influence of several tree traits on rainfall partitioning in temperate and boreal forests: A review. Annals of Forest Science, 66, 602p601-602p611.

2) Boldrin, D., Leung, A.K. and Bengough, A.G. (2017). Correlating hydrologic reinforcement of vegetated soil with plant traits during establishment of woody perennials. Plant and Soil, 416, 437 - 451.

3) Boldrin, D., Leung, A. K. and Bengough, A. G. (2018). Effects of root de-hydration on bio-mechanical properties of woody roots of U. europaeus. Plant and Soil, 431, 347 - 369.
4) Carrier, W. D. (2003). Goodbye, Hazen; Hello, Kozeny-Carman. Journal of Geotechnical and Geoenvironmental Engineering, ASCE, 129(11), 1054-1056.

5) Gallipoli, D., Wheeler, S. J. and Karstunen, M. (2003). Modelling the variation of degree of saturation in a deformable unsaturated soil. Géotechnique, 53(1), 105-112.

6) Gardner, W. R. (1965). Dynamic aspects of soil-water availability to plants. Annual Review of Plant Physiology, 16, $323-342$.

7) Leung, A. K., Boldrin, D., Liang, T., Wu, Z., Kamchoom, V. and Bengough, A. G. (2017). Plant age effects on soil infiltration rate during early plant establishment. Géotechnique, 68(7), 646 - 652.

8) Liang, T., Bengough, A. G., Knappett, J. A., Muir Wood, D., Loades, K. W., Hallett, P. D., Boldrin, D., Leung, A. K., and Meijer, G. J. (2017). Scaling of the reinforcement of soil slopes by living plants in a geotechnical centrifuge. Ecological Engineering, 109(B), 1917 - 207.

9) Ng, C. W. W., Leung, A. K. and Ni, J. (2019). Plant-Soil Slope Interaction. Taylors \& Francis. ISBN: 9781138197558.

10) Ng, C.W.W., Ni. J., Leung, A.K., and Wang, Z.J. (2016). A new and simple water retention model for root-permeated soils. Géotechnique Letters, 6(1), $106-111$.

11) Ni, J. J., Leung, A. K. and Ng, C. W. W. (2019). Modelling effects of root growth and decay on soil water retention and permeability. Canadian Geotechnical Journal. In press.

12) Rahardjo, H., Satyanaga, A., Leong, E. C., Santoso. V. A. and Ng. Y. S. (2014) Performance of an instrumented slope covered with shrubs and deep-rooted grass. Soil and Foundation, 54, 417-425.

13) Scanlan, C. A. and Hinz, C. (2010). Insight into the processes and effects of root induced changes to soil hydraulic properties. In $19^{\text {th }}$ world congress of soil science, soil solutions for a changing world, Brisbane, Australia, 41-44.

14) Stokes, A., Atger, C., Bengough, A. G., Fourcaud, T. and Sidle, R. C. (2009) Desirable Plant root traits for protecting natural and engineered slopes against landslides. Plant and Soil, 324 (1), 1-30.

15) van Genuchten, M. T. (1980). A closed-form equation for predicting the hydraulic conductivity of unsaturated soils. Soil Science Society of America Journal, 44(5), 892-898.

16) Vanapalli, S. K., Fredlund, D. G., Pufahl, D. E., and Clifton A. W. (1996). Model for prediction of shear strength with respect to soil suction. Canadian Geotechnical Journal, 33, $379-392$.

17) Vergani, C. and Graf, F. (2015). Soil permeability, aggregate stability and root growth: a pot experiment from a soil bioengineering perspective. Ecohydrology, 9(5), 830 - 842.

18) Yang, Y., Chen, L., Li, N. and Zhang, Q/ (2016) Effect of root moisture content and diameter on root tensile properties. Plos One, 11(3), e0151791. 